\title{
Emotional Intelligence among Children with Smartphone
}

\author{
Nurul Syazana Samsul Baharin*, Nur Aniza Mohd Lazim, Hema \\ Zulaika Hashim, Siti Norfatulhana Ishak and Ruhil Nadiah Abu \\ Bakar
}

Faculty Art \& Design, Universiti Teknologi MARA (UITM), Malaysia

\begin{abstract}
Emotional intelligence refers to the ability to identify, evaluate, control and express emotions in various situations. It can be categorised to five essential elements which consists of: Self Awareness, Self-Regulation, Motivation, Empathy and Social Skills. For children, emotional intelligence is important as it can improve their self-awareness, manage their stress, build empathy, and communicate effectively as well as making good decisions. This study will explore the correlation between children and smartphone addiction with their emotional intelligence. Three psychology laboratories/experiments were conducted using multi video recorder and recording devices from different angles to observe the behaviours of five children aged five to nine years old in two situations: the one with the present of smartphone and without the smartphone. Results showed that children display more interest in communicating, playing, creating conversations, and are more cheerful without the present of a smartphone. The children have the potential in socializing, were aware about their surroundings and show more empathy when they are not encircled with smartphones. The result from this behaviour study may create awareness of the impact of smartphone addiction among children and to increase understanding and concern for the emotional intelligence of the children who are growing up with the luxury of having smartphones.
\end{abstract}

Keywords: Emotional Intelligence, Smartphone addiction, Children, Behaviour

\section{Introduction}

Gadgets like smartphones are one of the advanced tools which have the same function as computers and are more portable too. According to the statistics done by a mobile economy in 2019, 2.71 billion people in the world are using smartphones. Some even estimate that people check their phone as much as 150 times a day or maybe more. It has become a necessity as they are exceptionally useful for us. Even for parents, they use smartphones to help them manage their children. For instance, giving them the smartphones while dining out to make the children behave quietly on their seats while watching videos on YouTube or let them play games on the smartphones. Normally, children will focus on the screen and be able to keep quiet for some time. Children these days are already being exposed to gadgets but spending too much screen time might lead them to have a lack of emotional intelligence (Christakis, 2018).

According to Goleman (1995), emotional intelligence is recognizing, understanding, and controlling our own emotions. Fundamentally, we are conscious of our emotions that lead to our behaviour whether positively or negatively as it can influence others' emotions too. Emotional intelligence consists of five elements skills that are important for us such as, self-awareness, self-regulation, motivation, social skills, and empathy (Goleman, 1995).

- Self-awareness: to understand what he or she feels at the time.

- Self-regulation: to control their emotions before talking or giving their impulsive actions towards others. 
- Motivation: how he or she feels to complete the goals that they have set in their life.

- Empathy: how they understand and are aware about others feelings.

- Social skills: how they know to get a positive thought from other people and manage to have relationships with people surrounding them.

Timsit (2019) said in one of her articles, starting from three to thirteen years old, children undergo a phase of learning and absorbing knowledge from their surroundings, formally or informally. Yet, due to the advanced technology and the excessive usage and exposure of using smartphones, it could destroy the children's need to learn, managing social behaviour and it can also replace their visual motor skills for them to learn in math and science (Lin, 2017).

One study had been conducted by Motanari (2017) about the clinical and psychological consequences of excessive screen time on children that had proven strong correlation between excessive screen-time and obesity, sleep disorders, aggression, poor social skills, depression, and academic underachievement. Furthermore, Cho and Lee (2017) in one of their studies about the influence of smartphone addiction to young children on problematic behaviours and emotional intelligence had proven that the addiction has tendencies to display problematic behaviours and impede emotional intelligence. To support that, based on a study published by the Journal of the American Medical Association (JAMA), children from the age of two until five years old who engage more than 2.5 hours per day on gadgets like smartphones, will show tendency of failing to develop language ability, communication, problem-solving and motor skills. Cha \& Seo (2018) also stated that the addiction could lead them to negativity activities. This negativity might impair them in the future as they lack emotional intelligence. Radesky (2014) said in his journal that the addiction could block their creativity and imaginations as well as their visual motor skills development. National Institutes of Health has also found out that it will also lower children's cognitive skills if they spend more than two hours a day on smartphones.

It is apparent that smartphone addiction could affect children's emotional intelligence because it limits their development of social behaviour and empathy as they grow up. Children who are so immersed and have their eyes locked on the screen, have the inclinations to be inactive physically and would rather spend time alone and indoors. Although many parents are eager to see their children develop in academics such as reading, writing, and counting, they often are not well informed of the importance of having good emotional intelligence. Emotional intelligence can be acquired through socialization so that the children will learn to share, negotiate, and handle their complex emotions. For instance, let's say the children play games and lose in the game, their emotional intelligence will help them to react to the situation, be it positive or negative. However, there are still parents who still do not limit the screen time of their children, due to their busy lifestyle or busy working. This could be the impact from the lack of knowledge of the importance of emotional intelligence development in children. Apart from that, smartphone addiction can also affect children's sleep pattern and their relationship between family and friends. The World Health Organization (WHO) and American Academy of Paediatrics (AAP) stated that children from two until five years old are suggested by psychologists to spend on screen time for just one hour a day. Thus, the objective of this paper is to show correlation between the impacts of smartphone addiction among children's emotional intelligence development.

\section{Methodology}

The study was conducted from May until July (2020) using three sets of experiment videography and different set places to prove that smartphone addiction has effects on children's emotional intelligence. Observations were made to study their body language, verbal, and non-verbal reactions towards the five emotional intelligence aforementioned. Five children from age five until ten years old were chosen as the respondents 
whereby the researcher placed them into two separate rooms to study their behaviour with the present of smartphone and without it. Cameras were set up and placed discreetly from the children's knowledge.

The researcher put the table in the middle of the room and each one of the children was given a smartphone to play for 30 minutes. In the first 15 minutes, the researcher tried to distract them by making the pencil box fall from the table to see whether they were aware of the incident. After 10 minutes had passed, the researcher once again tried to distract them again by reading a children's book and walked around them to see their responses. After 30 minutes the researchers then took the smartphone away from them and then allocated another 30 minutes for them to play with any toys on the table to see their reaction. The deliberate distractions were made during the time to see their reactions without the presence of smartphones.

\section{Result and Discussion}

\section{First trial}

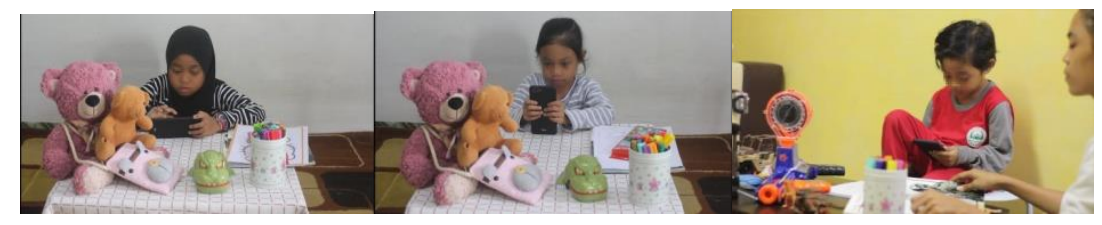

Figure 1

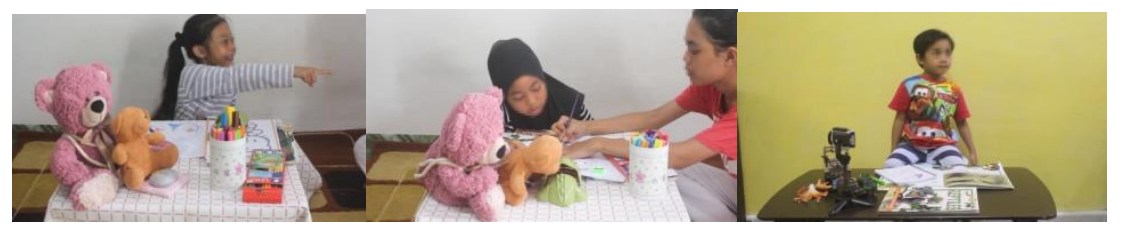

Figure 2

Based on the first trial of the observation, three children were involved as the respondents. Referring to Figure 1, toys and smartphones were placed on the table, and the children can play with the smartphones for 30 minutes. Children had no reaction to their surroundings when the researcher deliberately dropped the pencil box from the table, playing with the toys, walked around them and even when the researcher was reading a children's book besides them. This happened because they have their eyes locked on the screen. Thus, the children did not show the five domain signs of emotional intelligence.

After 30 minutes, smartphones were taken away and leaving the children with only the toys and books in the room to play for about another 30 minutes. Based on Figure 2, the children started to react better with their surroundings when the researcher employed the same distractions like deliberately dropping the pencil box from the table, playing with the toys, walking around them and even reading a children's book besides them. The children also showed empathy by helping the researcher to pick up the pencil box from the floor. Apart from that, they also communicate better with the researcher. 


\section{Second trial}

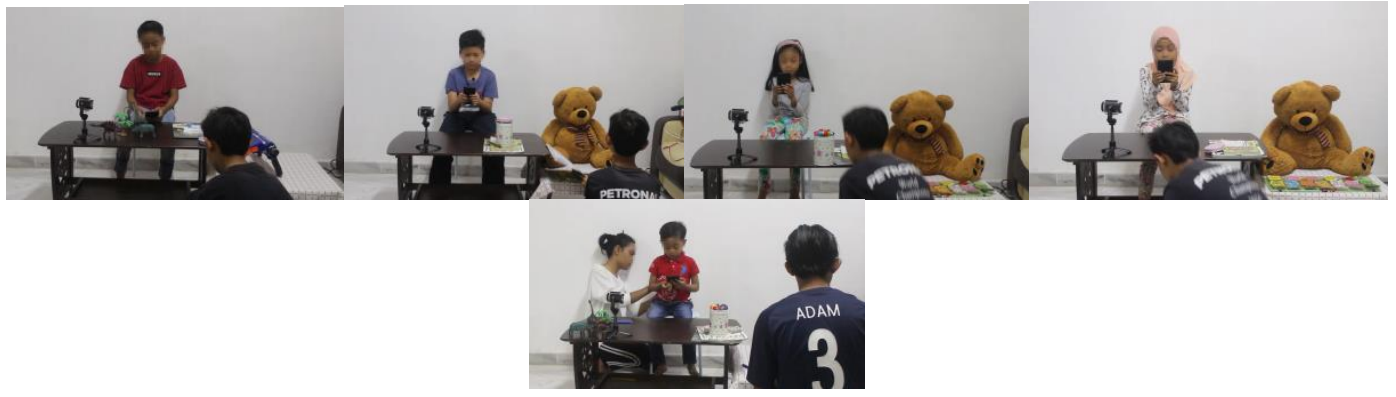

Figure 3

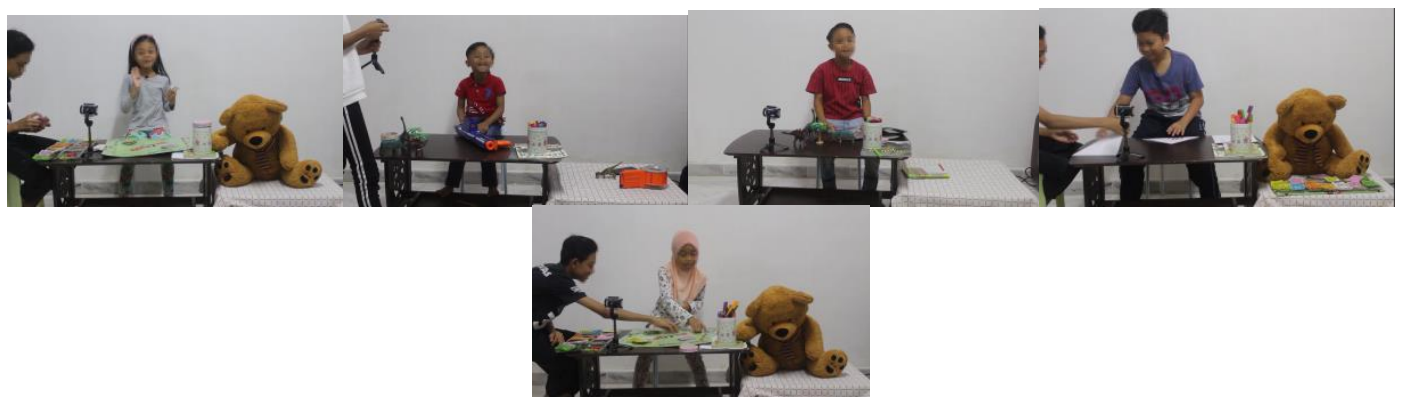

Figure 4

For the second trial, the same method as the first trial was employed but involving five children for the experiment. Two hidden cameras were set up for observation. Smartphones were given in the first 30 minutes and were taken away after that to see how they would react to toys and books on the table. For the second trial, the research placed a board game, Monopoly, and papers for origami. Both were ignored initially with the present of the smartphone. After the smartphones were taken away, the children showed interest in the board game and asked for help on how to play it. Others even showed their skills in origami and shared it with the researcher. 


\section{Third trial}

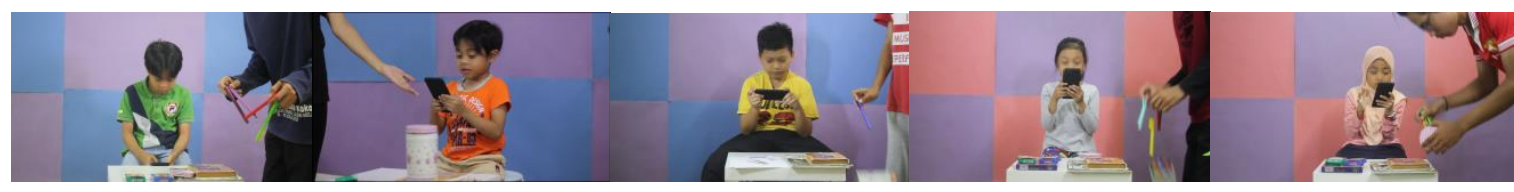

Figure 5

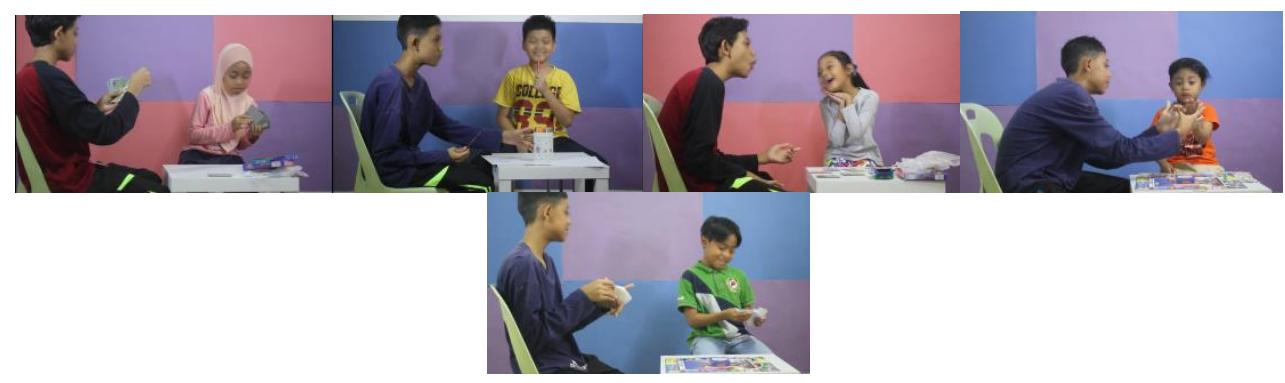

Figure 6

For the third trial, same methods were being used with the additional colourful background in the setting. Besides toys and books, the board game, Monopoly, and family card games were placed on the table. Just like in the first and second trial, children displayed no reactions to the distractions when they are focusing on the smartphone (Figure 5). However, after the smartphones were taken away, they turned to the objects on the table. The children have reacted to the distractions made intentionally by the researcher and displayed a sense of empathy by helping to pick up the pencil box from the floor. Some of the children were given a task to play the family card games and they have shown more improvement in their communication skills. This time the children requested to play the Monopoly game, like the previous time. While playing, they managed to control their own emotions even when they lost in the game. The children even were more cheerful and interactive without the smartphones (Figure 6).

From this study, it can be concluded that the EQ (Emotional Intelligence) is important in children's development. Based on the videos of the experiment, the children were being ignorant of the situations around them when they were too focused on their smartphones. They failed to show feelings or reactions of their surroundings. This clearly showed the danger of giving them too much of a screen time. Without the presence of the smartphones, children can slowly learn to cultivate their emotional intelligence in the five domains. Based on this experiment, without the smartphones, the children were able to react to the intentional distractions by the researcher, by helping to pick the fallen pencil box and even socialize with the people around them better. In addition, the children showed a motivation to finish everything they have started in which it can help them feel successful, more focused on their effort and will eventually help them to go out of their comfort zone. The children learned about self-awareness and self-regulation without their knowing in which they learn to understand themselves better and to handle their different types of emotions during the experiment.

\section{Conclusion}

It can be concluded that smartphone addiction can affect the emotional intelligence of the children's development. The children reacted positively to their surroundings without the presence of the smartphones. They socialize better, show more empathy, and even exhibit cheerful personalities. Based on the results of this study, parents need to be aware and to realize that smartphones can affect the children negatively. This is not to say that gadgets like smartphones should be banned totally from children, but parents need to set limits when it comes to the screen time. There are in fact many useful educational applications on smartphones where the children can learn. All the parents need to do is to put a limit to the screen time and to monitor the activities on the smartphone. 
Parents should spend time with their children, for example, doing activities together even doing the house chores at home could foster their emotional intelligence. There are so many activities available for parents to do with their children, for instance, reading books together, playing board games or even cooking together. Besides that, parents should also expose their children to things such as outdoor activities or playgroup dates to help them socialize with others to nurture their emotional intelligence. By doing outdoor activities, the children can improve their five senses and enhance their sensory motor skills. For future reference, more studies in this topic are needed to help the future children to be more active and responsive in this progressive digital world.

This research was supported by Faculty of Art and Design, Universiti of Teknologi MARA. We thank our team who provided insight and expertise that greatly assisted the research, although they may not agree with all of the interpretations/conclusions of this paper. We thank to the supervisor for assistance with technique and methodology, and for comments that greatly improved the manuscript. We would also like to show our gratitude to the institution for sharing their pearls of wisdom with us during the course of this research, and we thank 3 "anonymous" reviewers for their so-called insights. We are also immensely grateful to for their comments on an earlier version of the manuscript, although any errors are our own and should not tarnish the reputations of these esteemed persons.

\section{References}

AAP (2016), AAP Announces New Recommendations for Children's Media Use.

https://www.healthychildren.org/English/news/Pages/AAP-Announces-New-Recommendations- for-ChildrensMedia-Use.aspx.

Cha, S.-S., \& Seo, B.-K. (2018). Smartphone use and smartphone addiction in middle school students in Korea: Prevalence, social networking service, and game use. Health Psychology Open, 5(1), 205510291875504. https://doi.org/10.1177/2055102918755046

Cho, K., \& Lee, J. (2017). Influence of smartphone addiction proneness of young children on problematic behaviors and emotional intelligence: Mediating self-assessment effects of parents using smartphones. Computers in Human Behavior, 66, 303-311. https://doi.org/10.1016/j.chb.2016.09.063

Child Development: Self-Awareness. (2015). doi:10.4135/9781506350745

Christakis, D. A., Ramirez, J. S., Ferguson, S. M., Ravinder, S., \& Ramirez, J. (2018). How early media exposure may affect cognitive function: A review of results from observations in humans and experiments in mice. Proceedings of the National Academy of Sciences, 115(40), 9851-9858. https://doi.org/10.1073/pnas.1711548115

Domingues-Montanari, S. (2017). Clinical and psychological effects of excessive screen time on children. Journal of Paediatrics and Child Health, 53(4), 333-338. doi:10.1111/jpc.13462

Goleman, D. (2006). Emotional intelligence. New York: Bantam Books.

Lin, L.-Y., Cherng, R.-J., \& Chen, Y.-J. (2017). Effect of Touch Screen Tablet Use on Fine Motor Development of Young Children. Physical \& Occupational Therapy In Pediatrics, 37(5), 457-467. https://doi.org/10.1080/01942638.2016.1255290

Radesky, J. S., Schumacher, J., \&amp; Zuckerman, B. (2014). Mobile and Interactive Media Use by Young Children: The Good, the Bad, and the Unknown. Pediatrics, 135(1), 1-3. doi:10.1542/peds.2014-2251

Timsit, A. (2019, August 21). Smartphones are disrupting the crucial connections between parents and their babies. Retrieved October 08, 2020, from https://qz.com/1674835/technology-is-interfering-with-the-parentchild-relationship/Emotional Intelligence (2002). Understanding the Intelligence Component of Emotional Intelligence. doi:10.7551/mitpress/2704.003.0006

World Health Organization. (2015). Public health implications of excessive use of the internet, computers, smartphones and similar electronic devices: Meeting report, Main Meeting Hall, Foundation for Promotion of Cancer Research, National Cancer Research Centre, Tokyo, Japan, 27-29 August 2014. World Health Organization. 